Article

\title{
'It's Something Posh People Do': Digital Distinction in Young People's Cross-Media News Engagement
}

\author{
Jannie Møller Hartley \\ Department of Communication and Arts, Roskilde University, 4000 Roskilde, Denmark; E-Mail: jath@ruc.dk
}

Submitted: 22 December 2017 | Accepted: 9 March 2018 | Published: 25 May 2018

\begin{abstract}
In this article, I analyse digital distinction mechanisms in young people's cross media engagement with news. Using a combination of open online diaries and qualitative interviews with young Danes aged 15 to 18 who differ in social background and education, and with Bourdieu's field theory as an analytical framework, the article investigates how cultural capital (CC) operates in specific tastes and distastes for news genres, platforms and providers. The article argues that distinction mechanism not only works on the level of news providers and news genres but also on the level of engagement practices-the ways in which people enact and describe their own news engagement practices. Among those rich in CC, physical, analogue objects in the form of newspapers and physical conversations about news are seen as 'better' that digital ones, resulting in a feeling of guilt when they mostly engage with news on social media. Secondly, young people with lower CC discard legacy news, which they see as elitist and irrelevant. Thirdly, those rich in CC are media and news genre savvy in the sense that it makes them able to critically evaluate the news they engage with across platforms and sites.
\end{abstract}

\section{Keywords}

engagement; diaries, distinction, field theory; media; news; social media intermediaries; young people

\section{Issue}

This article is part of the issue "Rethinking Media and Social Space", edited by André Jansson and Johan Lindell (Karlstad University, Sweden).

(C) 2018 by the author; licensee Cogitatio (Lisbon, Portugal). This article is licensed under a Creative Commons Attribution 4.0 International License (CC BY).

\section{Introduction}

I watch Monte Carlo. Or in fact, I don't watch it to keep track of what is going on, I watch it because it's funny. Sometimes I wish, I knew more about what's going on in society. If you follow politics, you seem clever. It's like it's prestigious to be engaged in society. But that's so ironic, since we are many who thinks that the politicians are just a bunch of idiots.

This young boy of 17 years describes his daily routines of using various media and news during a normal day in his life in an interview carried out at the boy's school in the spring of 2015. The talk show Monte Carlo is a Danish satirical television show that comments on the everyday news agenda, with two young hosts making funny comments about things politicians have said, (political) decisions made and popular news stories in general, which they spin into satirical jokes.
The programme in itself, which started as a radio programme on a public service channel dedicated to popular music primarily, would not, in any surveys of this boy's news consumption patterns, be categorised as news. Nevertheless, this hybrid form of news is a source of information for this boy on what has been characterised by Elisabeth Bird as 'every day news talk' (Bird, 2011, p. 489). Sometimes he watches the show with friends, sometimes alone, but during the period in which the interviews were carried out, it was nearly always the topic of conversation the next morning in school or on Messenger during the show. If something was exceptionally funny, the boy would even share it on his Facebook wall or Snapchat it to friends, although he generally avoided sharing anything on Facebook, especially news: 'I don't really follow news', he said to me in an almost proud voice. 'It's something posh people do, and I feel like doing the opposite'.

Studies show that this Danish boy is not alone. Young people are found to be generally less active in seeking in- 
formation about what happens in society than older generations (Casero-Ripolls, 2012; Kohut, 2013; Newman, Fletcher, Kalogeropoulos, Levy, \& Kleis Nielsen, 2017). Research from several countries has shown that young people are less interested in news and less informed than their counterparts in earlier decades (Buckingham, 1999) and that the marginal significance of news and current affairs programmes in the life of young people indicates a rather limited social involvement (Horowitz \& Mindich, 2007). Concerned voices fear that the overall decreased interest in news is resulting in a decline in 'informed citizenship', (Buckingham, 2000, p. 2) and fragmentation of audiences (Tewksbury, 2005; Trilling \& Schoenbach, 2013). Other studies find, however, that frequent social media use among young citizens can function as a leveller in terms of motivating political participation (Holt, Shehata, Strömbäck, \& Ljungberg, 2013).

Irene Costera Meijer (2007) points to the fact that many of these empirical findings rely on self-reporting and that young people might get political information from many other places than traditional news (Costera Meijer, 2007, p. 4). Like Barnhurst and Wartella (1998), she supports the conclusion that young people experience news as just one genre out of many in the neverending flow of television images. Moreover, they do not draw a strict line between entertainment and information, and to develop their political awareness they rely on a much broader set of programs and media than just news in the classical sense. Young people's relationship with the news seems, Costera Meijer argues, to be paradoxical, in that they like to follow the news, as they feel it is something they ought to do, but they also find themselves tuning into more entertaining forms of watching news than the traditional news on television. However, they do not want these traditional news programmes to become more entertaining, as the news then seem less credible or even fake (Costera Meijer, 2007, p. 13). In Sweden, Malin Sveningsson finds a discrepancy between the young people's reported news consumption, when compared with their media diaries and the way in which they talked about news in social media, suggesting that they do not see the news they receive through social media as real news (Sveningsson, 2015). Quantitative surveys of people's news consumption patterns might then underestimate the importance of social media and other more popular genres of news, such as talk shows, for the level of news consumption among young people. What Sveningsson also finds are some interesting differences between how the young participants talk about news, but the differences are not analysed per se, and, thus, we are left with the question of why and how these differences occur and how they matter.

Research has shown links between class and news orientation; for example, socialisation into news consumption seems to be strong in homes with higher educated parents who regularly consume news and discuss these with their children (York \& Scholl, 2015). A recent Swedish study, not limited to young people, shows that those rich in cultural capital (CC) are more inclined to consume 'quality' news and neglect 'popular' news (Ohlsson, Lindell, \& Arkhede, 2017). News consumption seems indeed stratified across different socio-cultural groups in society. This goes for both motivation, skills and ability to consume news (Blekesaune, Elvestad, \& Aalberg, 2012; Holt et al., 2013; Ksiazek, Malthouse, \& Webster, 2010; Strömbäck, Djerf-Pierre, \& Shehata, 2013); and even though interest in both news and politics tend to increase with age (Hill \& Gauntlett, 1999), there is a need to further investigate the normative motives and reasons for engaging with news in a digital age as this interest or disinterest develops. Furthermore, it seems meaningful to investigate not just young people as one group, but also the differences between them, as these differences are likely to continue into their adult lives, providing a more sociological explanation to the wellestablished knowledge on news avoiders and news seekers and the possible consequences for democratic citizenship (e.g., Ksiazek et al., 2010; Lee \& Yang, 2014; Strömbäck et al., 2013).

This article takes a sociological approach and investigates how young people might be unequally equipped to manoeuver in the legitimate news culture of the social space they inhabit. Like previous studies of distinction in news consumption (Hovden \& Moe, 2017; Lindell \& Hovden, 2016; Lindell \& Sartoretto, 2017; Ohlsson et al., 2017), I draw upon the cultural sociology of Bourdieu and conceptualise news engagement practices and preferences as part of broader, potentially classified, tastes and lifestyles that serve the function of legitimating social differences (Bourdieu, 1984).

This article contributes, in a qualitative way, to this line of research, but it argues for a need to shift focus to also include distinction practices-the attitudes and values to the ways we engage with news, in the analysis of fragmented and dispersed news consumption patterns. This has been done within studies of consumption and appreciation of art (Holt, 1997), but this study shows similar mechanisms of difference in current news engagement practices, not just between news outlets and genres, but also between technological devices and platforms and the ways of describing the use of these for engagement with news on various platforms and devices. Hence, the article is a step on the way of updating field theory, paving the way for further analysis of emerging forms of capital in a high choice digital news media environment.

\section{News and Media Engagement as Distinction}

Pierre Bourdieu's analysis of media consumption, which is generally seen as part of the larger field of cultural consumption, can be found in mainly Distinction (1984) and The Field of Cultural Production (1993). But in several of his works, the workings of the media are integrated into his overall analysis of the structural factors that influences everything from choice of films to what news- 
paper we subscribe to and how the middle class pose on a photograph (Bourdieu, 1993, 1998, 1990a).

The young people's digital news practices and preferences are understood in this study as part of their lifestyles and analysed with their habitus as foundation. The habitus is created by an individual's social background, education and experiences, an embodiment of the persons' cultural capital. CC and habitus are expressed by acts of distinction: ways to communicate and create one's identity by showing taste or distaste for cultural practices and artefacts. In a field theory, perspective, media and news practices must be related to our position in the social space, on the same time stratifying and affecting that exact position in the social space, the habitus. It is a cluster of continuous, but still changeable, dispositions (Bourdieu, 1990b, p. 53), which functions simultaneously as a system of power relations and as a symbolic system in which distinctions of taste become the basis for social re-production (Bourdieu, 1984). Bourdieu described the mechanisms behind these practices in this well-known quote:

Taste classifies, and it classifies the classifier. Social subjects, classified by their classifications, distinguish themselves by the distinctions they make, between the beautiful and the ugly, the distinguished and the vulgar, in which their position in the objective classifications is expressed or betrayed. (Bourdieu, 1984, p. 6)

Digital distinctions, then, are acts of distinction, taste and distaste in an increasingly digital sphere of cultural consumption. As such, we never just (rationally) choose from the number of media made available for us then, as suggested by uses and gratification approaches (Katz, Blumler, \& Gurevitch, 1973; LaRose \& Eastin, 2004) or studies of media repertoires (Hasebrink \& Popp, 2006; Kim, 2014). Elsewhere, digital distinction has been studied as the choices made by similar university students in terms of socio-economic status between different websites, relating them to other (also offline) cultural practices (Bengtsson, 2015). It has also been studied in the context of how internet use is related to democratic behaviours and engagement, and how different groups with diverse economic and CC use and navigate digital media and the possible democratic consequences hereof, often referred to as the 'digital divide' (Gripsrud, Hovden, \& Moe, 2011; Hargittai, 2010; Hollingworth, Mansaray, Allen, \& Rose, 2011; Kalmus, Realo, \& Siibak, 2011; Meyen, PfaffRüdiger, Dudenhöffer, \& Huss, 2010; Robinson, 2009; Zillien \& Hargittai, 2009). What this body of literature tells us is that CC matters when manoeuvring the digital sphere, but this cultural approach has only very recently been applied to the study of people's distinctions and classifying practices when engaging with news. In a recent qualitative study of young people in Sweden and Brazil, Lindell and Sartoretto found that different social groups monopolise completely different news practices and that these are highly socialised via home and school experiences with news (Lindell \& Sartoretto, 2017, p. 1). Other studies of distinction in the field of news have shown how CC endangers patterns of taste and distaste for different online news providers (Ohlsson et al., 2017) and how that even in a high-choice environment, media choices and practices become included in the repertoires that work to legitimate social differences (Lindell \& Hovden, 2017).

As this study is a qualitative one, I seek to understand the role of inherited $\mathrm{CC}$, as the news engagement practices are in the process of being formed. The qualitative approach also enables me to contrast the inherited CC with how the young people evaluate and value their own news and media practices, which indicates the legitimate and illegitimate ways of engaging with news in different social settings.

On the basis of two larger empirical studies of cultural tastes in Britain and Denmark, Prieur and Savage show that although taste for classical high culture might be in decline, this does not mean that class differences in cultural orientations have declined (Prieur \& Savage, 2013 , p. 249). However, they have changed. They suggest that:

In such processes some social agents will be ahead of changes, having developed effective reproduction strategies, while others will stick to evaluation schemes that once gave themselves or ancestors their privileges but today are in the course of becoming obsolete. (Prieur \& Savage, 2013, p. 254)

They dispute the theories of the omnivore raised by several studies, the argument that people today can embrace both high- and low-brow genres, as a dispute of these forms of distinction processes (Bennett, Savage, Silva, Warde, Gayo-Cal, \& Wright, 2008; Chan \& Goldthorpe, 2005). Prieur and Savage suggest the term of 'knowing' as a form of emerging cosmopolitan form of CC to capture the subtle differences in the capacity to range over cultural forms in an ultimately discriminating way (Prieur \& Savage, 2013, p. 256). In line with Holt (1997), they argue that the changes may imply a displacement of how distinction is achieved, with less emphasis on the choices of particular cultural objects (such as newspapers or certain media brands) and more on the way to relate to these objects. Theoretically, this article aims to contribute to this line of research focussing on 'knowing' the news in a digital high-choice environment and, hence, open non-media-centric (Morley, 2009) diaries in combination with qualitative interviews proved a valuable methodological path.

\section{The Methodological Framework}

The project was situated around Copenhagen, but it also included participants living and going to school in the suburbs and the countryside a few hours from the city. 
To reach people from varying backgrounds, four schools were selected: two colleges with a focus on students continuing to university, a production school for dropouts from the regular secondary schools, leading to craft internships and a boarding school for students age 15 to 16 who have not yet made their choice of further education.

The methodology chosen was open ended diarywriting, which took place over a period of 8 weeks in May and April 2015 and in which a total of 36 of the young people from different social backgrounds participated. There was a dropout, and thus a total of $21 \mathrm{com}$ pleted the period of writing the diaries. Of these, 15 were female and 6 were male. During the diary period, the participants were asked to stay off media for one week and reflect on this before and after.

For this study, a website on a closed university server was created through which the participants could access their online diaries. The diaries were closed to the public and could only be read by the participants individually and me. The purpose of placing the diaries online was to make the diary writing process as convenient as possible for the participants and to expand the possibilities related to writing the diary (e.g., to add hyperlinks, upload pictures and sound or change the visual appearance of the diary).

Some participants uploaded only once a week, and some uploaded up to 24 times during the period of 8 weeks. The purpose of this unstructured approach was non-media centric (Morley, 2009), and the advantage is that it enables the researcher to catch and investigate spontaneous news engagement as it is entwined with the consumption of other media content and the differences in these practices. Coleman (2006) argues that news for people seem to be related to a very specific form, and it seems that even the very definition of news is at stake here. Thus, a non-media centric methodological framework means that the study does not operate with a definition of news as a specific genre with some certain attributes and normative expectations attached to it, but rather an emic and audience centred understanding of news and media could emerge in the context of other cultural practices and everyday life of young people. Sveningsson notes that diaries also reveal news consumption patterns that the participants either forget or do not see as news consumption, for example, checking the phone or watching news with their parents (Sveningsson, 2015).

To achieve a group of participants with varying amounts of $\mathrm{CC}$, all participants answered a survey before entering the diary project. As a consequence of their young age, CC was operationalised as their sociocultural background, for example, parent's occupations and incomes, cultural consumption habits in their parents' homes and the participant's choices of education (Bourdieu, 1984).

The participants are of course not representative of all young Danish people. According to their own estimations in the survey, their news consumption was similar to the average Danish person aged 12- to 18-years- old (Slots- og Kulturstyrelsen, 2017). They are neither non-users or extremely high users of news and they were all, apart from one participant, inherently crossmedia (Schrøder, 2011). None were members of political organizations.

For the purpose of this article, where space is limited, I distinguish between HCC (high cultural capital) and LCC (low cultural capital) participants, as done by Holt (1997), who argues for several dimensions of 'knowing' and positioning strategies varying according to $\mathrm{CC}$. Naturally questions of class cannot be reduced to low and high CC, as the social field is much more multi-faceted. In the material presented here there are also lots 'in between', and some participants seem richer in CC than others in the same group. However, there is an urgent need to investigate how CC seems to be transforming, as the number of choices is expanding, and hence how new forms of CC might be emerging in this context. What is cool one day might be outdated the next, and what is outdated, becomes kitsch. If it is appropriated and consumed in the right way. In order to catch and explore these subtle differences, it has been useful to contrast the forms of engagement by dividing the participants into HCC and LCC. The analytical points about how CC matters for the ways taste and distaste is enacted cannot be generalised to all young people but can provide a starting point for such an analysis of dimensions of taste within a certain social field of media- and news consumption, in this case, the Danish social field, of which the young diarists are a part.

\section{Analysis}

\subsection{News at Home and in Schools}

Not surprisingly, and also confirming what we know from earlier studies (Costera Meijer, 2007; Newman et al., 2017; Sveningsson, 2015) the analysis show how social media, and especially Facebook, is the dominant media platform (mentioned several times in each of the diary entries) from which they access and engage with news. The interviews and diaries showed, similar to Sveningsson's study (2015), that the immediate network matters in terms of how young people access news, but for participants in this study, these networks would also be of a global character. For all participants, friends from abroad played a significant role, even people that they had never met outside the digital realm.

I spent a lot of my time on YouTube. All my news and information I get from there. I'm very interested in physics, so I spent a lot of time watching documentaries. Reddit is my second most used source of news. We have a community here, where we share everything and discuss with other people. You can mention any subject, and there will be a Reddit forum for it.

Participants rich in CC were also introduced to news in schools, this was particularly the case for the boarding 
school students. They would start off every morning with an assembly with all the students discussing the news agenda of the day-news that they would later follow up on or work with in the class discussions:

One of the teacher's cats were run over today. And it completely took over what we talked about all day. None of the other news stories we heard about this morning at the assembly made the same impression. We heard about the policeman, who was not charged in Ferguson, we heard about Lykketoft [a politician, ed.] going to the UN. And about the file from Venstre [Government party, ed.] on how to spin the opposition. Especially the thing with Lykketoft surprised me, and I was so interested that I went to DR's app to read about it.

Also, they had a course called 'Global', where the teachers recommended using news in assignments and often moulded the class sessions according to what had been in the newspapers of the day. What is significant here is that the news the students get exposed to as 'news' were mostly political and concerned with national and global issues, asserting these as the legitimate form of news. For HCC participants, similar processes could be observed when they were at home with their parents.

Sveningsson (2015) notes how watching the news seems to be a way of spending time with parents, and this was also the case for the young people in this study, but differences between the LCC and HCC participants emerged. While the HCC participants specifically discuss some of these stories with their parents and enjoy this, the LCC participants did not in the same way see news as a bond between themselves and their parents. HCC participants also mentioned how their parents frequently read a subscription newspaper at the breakfast table and how they sit down and read some of the stories recommended by their parents. When asked directly about media in their homes, LCC mentioned noticing the free local newspaper in the pile of ads at home in their mum's house, or how the radio or a television is turned on in the kitchen in the morning. If they discussed media content with family, it would usually be television game shows, such as (Danish versions of) Big Bakeoff or X-factor, or sports, as also seen in the study by Lindell and Sartoretto (2017). In school, even though some of the LCC participants had a course in media, it was not focussed around news. Instead, it focussed around producing a glossy magazine with ads and satire, or the production of an ad for television. One girl was particularly occupied in her diary with her role as a reporter for $\mathrm{X}$-factor for a self-made YouTube channel. Another wrote about her blog, reviewing makeup and hair products, which-despite quite a lot of followers - was a secret to both her friends, family and her boyfriend.

This confirms the results of Lindell and Sartoretto (2017), who argue that attitudes to seeking news and keeping informed, as well as values related to news con- sumption and its relevance, are more likely to be passed on and reproduced as habitus, resulting in vastly different starting points for forming news practices (Lindell \& Sartoretto, 2017, p. 10).

\subsection{Individualisation of the News Engagement}

In a field theoretical framework, distinctive acts are those acts that strive to express difference towards that which is regarded as easy, common or mainstream (Bourdieu, 1984, p. 176). With almost every single member of the Danish population on Facebook, it is likely to be considered both easy and mainstream. Moreover, when something is enjoyed by the many, it is often rejected by the elite or those rich in CC. "I was so much more creative when not using FB. But I need to connect', as one HCC diarist put it after a week of being off all media. In the case of this study, HCC participants seemed to camouflage their excessive use of Facebook and distinguish themselves in other ways than abandoning the platform, since it is apparently 'too difficult' socially for them not to be on Facebook, mostly because of Messenger. Instead, HCC moulded their Facebook practices to differentiate themselves, for example, by not sharing news and personal information, sharing things that are widely shared, commenting, liking and distancing themselves from those who debate and share, for example, their parents. The following HCC participant expresses this in her diary after remarking how she had spent the evening reading a novel.

And what is BJ doing [her mother, ed.]. with her 43 years of age this evening? Indeed, she is on Facebook, sharing pictures of the ugly cat in the window. And what is KP [father, ed.], 42, doing? He is also on Facebook commenting on some half-racist-unreadablefull-of-mistakes-completely-unnecessary comments on the Facebook-page of some ridiculous politician. And then they say that I (!) spend too much time on Facebook. That I do not spend my time sensibly. Society is complaining that I do not spend enough time debating, that I am not active enough. But who can blame me for not taking part in this boring debate on Facebook. As if I want to waste my time on that.

The quote illustrates, of course, a generational gap between the girl and her parents, but in the material, these same distinctions were found among HCC participants towards other peers who share or debate what these HCC-young discard as irrelevant news. One girl, for example, was annoyed with one of the classmates who shared news about horses, and another boy was ranting in the interview about a girl his age sharing news stories about depression, 'just because she has a depression herself'.

LCC, however, reflect on the practicality of accessing a wide range of news, which is free and useful for them in their own lives. They talk positively about how their feed provides them with a fast overview of the news and 
how they see things that they would not otherwise have access to. They sometimes follow online debates with curiosity, but do not participate, not because they feel it's a waste of time like the HCC participants, but they don't feel they have anything to contribute with.

Despite the intense use of digital sources of news, $\mathrm{HCC}$ participants favour analogue objects of news consumption such as television (most often Public Service) and legacy newspapers, but also the physical presence and connections as well as physical talk about news and politics were seen as 'better' than-and preferred to-digital alternatives. Engaging with news on Facebook is described as 'waste of time', 'easy', 'a necessary overview', 'superficial', and even at times 'fake'. This indicates the superiority and legitimacy of other news platforms over social media platforms and that practices of using the same mass-distributor of news as Facebook is, are valued differently depending on the $\mathrm{CC}$ of the agents.

Amongst HCC participants, there was an urge to be or feel updated, which was described in positive terms when they could live up to it, and as frustration when they were less updated than they felt they had to be, as was often the case. Thus, being offline for a week came as a relief, since it gave them an excuse to be out of the loop, and they described it as 'interesting' and 'enlightening':

It was kind of nice to be without media, because normally you have to be updated on the news and stuff.

In the Swedish qualitative study (Sveningsson, 2015), we likewise saw how Twitter was considered a good source of news, because it could keep them updated constantly, but the LCC participants in the present study did not feel the same need to be updated, at least not on political news or human-interest news. Also, none of them were on Twitter, while Twitter was popular among those rich in CC.

In contrast, LCC participants saw the offline week as hard, impossible and odd. Many of them quit after just one day and some participants cheated. This also indicates that the negative judgements around Facebook by HCC participants made them more able to switch off, as it seems to conform with their norms. When these ideals of 'switching off' are not present or even resisted and contradicted by LCC participants, the attempt to stay offline became much more than just difficult. It became silly and pointless for them.

The participants seemed to understand news as the classical genre of quality news. As a consequence of this, LCC participants often did not see themselves as 'following the news', and although my material is too small to generalise, it seems to be especially the young men who distance themselves from news. At the same time, the diaries show how they regularly engage with news via game forums or sites like Reddit, or they follow sports (news). It seems that sometimes more popular news does not even qualify as news in their reflections and what they show distaste for is political news and genres more associated with quality news vis-à-vis more popular news genres. The differences between men and women can also be seen in Ohlsson et al.'s study, where women were more likely to consume quality newspapers, and men more likely to go for popular online news (Ohlsson et al., 2017). Another quantitative study from Sweden concludes that women tend to be richer than men in CC while men tend to be richer in economic capital (Lindell \& Hovden, 2017, p. 8). More research is needed, however, to investigate what is perceived as 'quality' and 'news' by various audiences themselves.

\subsection{Cosmopolitan vs. Local News Engagement}

The reasons for engaging with news given by LCC participants were much more about their social life ('talking to other people'), entertainment and duty ('I feel, I should'), and the occasional engagement with news on various (mostly online) platforms is described as 'fun', 'cosy' (hygge) ${ }^{1}$ and as 'wasted time in between doing other things', similar to Sveningsson's study, where participants also described news consumption as a 'pastime' (Sveningsson, 2015). LCC participants emphasised news consumption on social intermediaries for practical reasons, like seeking news that is immediately usable in their own lives, such as a story of a man being attacked in the local neighbourhood or news stories on television shows they follow.

In contrast to this, HCC participants engage with news because of actual, or at least expressed, interest in news and politics and society around them. News on homosexuality in Uganda or the Ferguson trial in the US, among other things, are reflected upon in the diaries, which they then relate to themselves coming out as homosexual or racism in Denmark. The HCC participants display a sort of cosmopolitan outlook; in the diaries they write about how media tells them all the things they ought to do, for example, how the news they engage with tells them to not to waste food, to protect the planet, to obtain an education and not to be lazy. HCC participants reflect on how they feel enormously privileged and, at the same time, extremely obliged to act and worry.

I have access to all the information I could want, via internet, books, newspapers, television, radio and so on. I feel safe, I'm happy, I'm healthy, in short, I'm privileged. And yet in some way I feel an obligation. First and foremost to do something about this enormous inequality in the world, which means that I have this fantastic privileged life, while others suffer and cannot cover the most basic needs.

Instagram, Tumblr and Snapchat tell them how to look, what to eat, how to have fun and have an otherwise

\footnotetext{
${ }^{1}$ The translation of the Danish word 'hygge' is often 'cosy', but it has a broader meaning of doing something social, often involving other people, something casual as supposed to serious and important.
} 
'perfect' life, which they were annoyed about and made them wish to leave social media and news on these platforms behind. This is similar to what we saw with Facebook.

Among some of the LCC participants, news avoidance was sometimes a deliberate and even antagonistic strategy, like, for instance, the diarist who proclaimed that news 'is something posh people do, and I feel like doing the opposite', as we saw in the opening vignette. The quote illustrates that consuming news in the classical understanding of news is associated with being 'posh' and this young boy deliberately and very consciously decides not to bother with that. LCC participants in this study have a disinterest in what they term the 'serious' news, which they describe as 'hard to follow' and 'irrelevant', or they describe how the content of the news does not really concern them.

I'm not a sort of...media-person or news-seeking in any way. I live in my own little world. I don't need it, so I don't even watch television. It's mostly Facebook that occupies me.

The LCC participants especially seemed to discard news on national politics and did not feel the same urge to keep up and, therefore, no bad conscience for not doing so. Choosing not to follow news is also a distinctive mechanism, separating them from all of those who find it important to keep up with the news. But, at the same time, the distinctive mechanism confirms the cultural and social hierarchy. This is similar to what was found in the study of Lindell and Sartoretto (2017), who emphasise that the social position matters to the extent to "which young people "buy into" the normative order that regards news as inherently 'good', valuable and worthwhile' (p. 17).

As Lindell \& Sartoretto (2017) also note, this resistance by participants poor in CC reify their position as subalterns in the social space. When they 'refuse what they are refused' they exclude themselves from the legitimate and dominant culture (Bourdieu, 1984, p. 471). According to Bourdieu, it is common that those with lesser CC resources are dismissive of, or antagonistic towards, the objects and practices of those with greater CC resources (p. 471). Bourdieu argues that CC secures the respect and esteem of others through the consumption of objects that are 'difficult' and so can only be consumed by those few who have acquired the ability to do so (p. 471).

Distinction mechanisms were also visible when the participants referred to sites they follow on social media. Where LCC like to follow pages that give them a broad, free and fast overview of the news, HCC participants talked positively about providers with more specific profiles, which suit their personal interests. A site like Dagens.dk (online only newspaper) and often local online sites are mentioned by LCC participants who discarded Politiken (a left-liberal daily) and other big sub- scription dailies. Again, the material is too small to generalise between global versus local links to CC, but in Lindell and Sartoretto's study, they also found an interest for local news among working-class young people in Sweden (2017). But as Sveningsson (2015) also notes, just because people declare that they do not follow news, it may just mean that they follow and engage with news that is not socially regarded and accepted as 'news', even by the LCC participants themselves.

\subsection{Referential vs. Critical News Engagement}

Interesting differences are also visible in the evaluations of the various sources of news. Amongst HCC participants we see, for example, that they specifically and much more so than LCC participants wish they could supplement the news the get on Facebook with other sources of news. However, newspapers and evening news, especially the public broadcaster DR, are described in positive terms; 'something you can trust', 'not the bullshit you get on FB' or like this comment on news via $\mathrm{FB}$ as an intermediary platform for news: 'it's much more reflecting to read an article than to just flick through headlines. It updates me, but I don't feel informed'. Hence, the negative distinctions reflected in the HCC young people's evaluations of Facebook as a platform filters down into their evaluations of Facebook as a platform for news engagement, and oppositions in the evaluations appear (updated/informed, trustworthy/crappy, in-depth/superficial). They show an awareness of the different profiles of the various news providers and what sources and news providers are legitimate in terms of trust and which ones they need to check by going to the original source.

I get most of my news from Tumblr, which most people might say is not a trustworthy source of information. But I always check where it comes from.

Interestingly, often the LCC participants found it hard to describe what sort of news outlets they accessed during the day and what forms of media devices they have in their homes. In many cases, they would not know if their parents kept a newspaper other than local, free commercial weeklies. Some of them would interchangeably describe TV2 news (the commercial public service station news channel) as TV-Avisen (the Danish public broadcaster), and while they followed a number of different news providers, they showed an indifference to who and what their news came from. 'It's all the same anyway', as one girl explained. In contrast to this, the HCC participants evaluated the news on a regular basis, showed extreme care as to what news stories to like or dislike in the Facebook feeds, if they ever liked any, and some of the HCC participants even deliberately liked certain news items that they would not normally do in order to 'cheat the Facebook algorithm', so it would not give them too many of the same types of news stories. On 
Tumblr and Instagram, they thought it was important to follow a diverse number of people; this showed an awareness of the fear of echo chambers or living in filter bubbles (Flaxman \& Rao, 2016; Pariser, 2011), whereas LCC participants did not in the same way find this important. Instead, they explained what they followed in terms of interests, sports, celebrities or fashion or other personal interests, such as gaming. As one LCC participant said, 'I just follow what inspires me'.

Almost all the participants follow a number of famous people, musicians, movie stars and blogger celebrities, but the HCC participants react strongly against their own practices in their diaries. Like we saw with their Facebook use, they feel guilty about it.

Following many famous people makes me very conscious about what I wear and how I look, and that annoys me.

The distaste for popular news by people rich in CC has been observed in previous studies (Lindell \& Sartoretto, 2017; Ohlsson et al., 2017) and can be observed at the level of which sites or people they follow, what they like and share on social media and how this is done. What is significant here is that the HCC participants in this study discard their own practices, which underlines the importance of analysing not just the actual news consumption and the selection between different platforms, but also the ways in which these practices are enacted.

\section{Concluding Remarks}

Different ideals and norms about news engagement appear in the empirical material from online open diaries and qualitative interviews with 21 young Danish persons between the ages of 15 and 18 in terms of how they evaluate their own news engagement practices. On the basis of this large in-depth qualitative material, this article has shown how Facebook and other social media intermediaries, as sources of news access, are connected to feelings of guilt, shame and resentment by those rich in CC. They have the means, privilege and acquired position to select from a variety of other news sources, and the analogue sources of news are generally regarded as 'better' than their digital alternatives. Young people rich in CC have an urge to feel updated and informed; a normative framework, which is introduced to them (and reinforced) in schools and in their homes. A position of HCC seems to make them seek news on human-interest issues, often with a national and global outlook. LCC participants seem to have a more materialistic and less symbolic use of news platforms and various sites, and, on a more general level, discard the need to stay updated and be informed, thus, refusing 'what they are refused' (Bourdieu, 1984, p. 471). They also have a more referential evaluation of their news engagement practices, where they find reasons for engaging with news if it is immediately useful and relevant in their own lives, which results in an of- ten quite strong distaste for political news on a global or national scale, as if it is 'just not for them'. News avoidance and news seeking has been established in earlier research, but this article contributes to a nuanced understanding of these mechanisms, which indicates that we need to go further in depth with people's motivations and reasons for engaging or disengaging. This article has done exactly that, and how these young people that are richer and poorer in CC differ in their evaluations of news in a digital sphere has been analytically conceptionalised in this article as digital distinction practices.

More research is needed to investigate not only how people's positions in social fields influence the choices they make but also how people enact those choices, the distaste and taste for certain ways of engaging with news and what new and emerging forms of capital we can observe in a digital high-choice media environment, where previous variables traditionally associated as high and low in the field of cultural consumption seems to be in decline (Prieur \& Savage, 2013). As the concept of cultural capital is gaining prominence, also in studies of media audiences, it is important to warn against a fixed understanding of the concept. Some survey responses (such as a priori liking for specific media products or brands which are then associated with highbrow or lowbrow tastes) run the risk of removing the relational nature of the concept. This article has taken a subtler approach in order to show that a widespread use of, for example, a certain platform such as Facebook for news, seem to transform how people enact their taste in news as a genre. This article also supports evidence that anti-elite currents in Scandinavian countries do not inhibit symbolic dominance of some news engagement practices over others. As suggested by Prieur and Savage (2013), knowing the different classifications, in this article termed 'critical news engagement', can be seen as a way of dominating certain practices in a discriminating way. As such it might not be the objects of news consumption, but the ways that these objects are rejected which marks them as exclusive. More research is needed to further explore the various and emerging forms of CC and class differences in digital news engagement practices coincide with specific positions in the social space and how they-in effectreinforce the structure of this space.

\section{Acknowledgments}

I would like to thank the anonymous reviewers and the editors of this thematic issue for their useful comments and encouragement. I would also like to thank the research groups 'Audiences and Mediated Life' and 'Journalism and Democracy' at Roskilde University for earlier comments on the draft for this article. Special thanks to Kim Schrøder, David Mathieu and Susana Tosca for their comments and to Martin Fehr Terkildsen and Leif Hemming Pedersen for help with the data collection. 


\section{Conflict of Interests}

The author declares no conflict of interests.

\section{References}

Barnhurst, K. G., \& Wartella, E. (1998). Young citizens, American TV newscasts and the collective memory. Critical Studies in Mass Communication, 15(3), 279-305. doi:10.1080/15295039809367049

Bengtsson, S. (2015). Digital distinctions: Mechanisms of difference in digital media use. MedieKultur, 31(58), 30-48.

Bennett, T., Savage, M., Silva, E., Warde, A., Gayo-Cal, M., \& Wright, D. (2008). Culture class distinction. London: Routledge.

Bird, S. E. (2011). Seeking the audience for news: Response, news talk, and everyday practices. In V. Nightingale (Ed.), The handbook of media audiences (pp. 489-508). Oxford: Wiley-Blackwell. doi:10.1002/ 9781444340525.ch25

Blekesaune, A., Elvestad, E., \& Aalberg, T. (2012). Tuning out the world of news and current affairs-An empirical study of Europe's disconnected citizens. European Sociological Review, 28(1), 110-126. doi:10.1093/ esr/jcq051

Bourdieu, P. (1984). Distinction-A social critique of the judgement of taste. Cambridge, MA: Harvard University Press.

Bourdieu, P. (1990a). Photography-A middle-brow art. Stanford, CA: Standford University Press.

Bourdieu, P. (1990b). The logic of practice. Standford, CA: Standford University Press.

Bourdieu, P. (1993). The field of cultural production: Essays on art and literature. Cambridge: Polity Press.

Bourdieu, P. (1998). Om Tv-og journalistikkens magt [On television]. København: Tiderne skifter.

Buckingham, D. (1999). Young people, politics and news media: Beyond political socialisation. Oxford Review of Education, 25(1), 171-184.

Buckingham, D. (2000). The making of citizens. London: Routledge.

Casero-Ripolls, A. (2012). Beyond newspapers: News consumption among young people in the digital era. Comunicar, 20(39), 151-158. doi:10.3916/C39-201203-05

Chan, T. W., \& Goldthorpe, J. H. (2005). The social stratification of theatre, dance and cinema attendance. Cultural Trends, 14(3), 193-212. doi:10.1080/ 09548960500436774

Coleman, S. (2006). Digital voices and analogue citizenship: Bridging the gap between young people and the democratic process. Public Policy Research, 13(4), 257-261. doi:10.1111/j.1070-3535.2006.00451.x

Costera Meijer, I. (2007). The paradox of popularity. Journalism Studies, 8(1), 96-116. doi:10.1080/ 14616700601056874

Flaxman, S. R., \& Rao, J. M. (2016). Filter bubbles, echo chambers, and online news consumption. Public Opinion Quarterly, 80, 298-320. doi:10.1093/ poq/nfw006

Gripsrud, J., Hovden, J. F., \& Moe, H. (2011). Changing relations: Class, education and cultural capital. Poetics, 39(6), 507-529. doi:10.1016/j.poetic.2011.09.007

Hargittai, E. (2010). Digital na(t)ives? Variation in Internet skills and uses among members of the "net generation". Sociological Inquiry, 80(1), 92-113. doi:10.1111/j.1475-682X.2009.00317.x

Hasebrink, U., \& Popp, J. (2006). Media repertoires as a result of selective media use. A conceptual approach to the analysis of patterns of exposure. Communications, 31(3), 369-387. doi:10.1515/ COMMUN.2006.023

Hill, A., \& Gauntlett, D. (1999). TV living: Television, culture and everyday life. London: Routledge.

Hollingworth, S., Mansaray, A., Allen, K., \& Rose, A. (2011). Parents' perspectives on technology and children's learning in the home: Social class and the role of the habitus. Journal of Computer Assisted Learning, 27(4), 347-360. doi:10.1111/j.13652729.2011.00431.x

Holt, D. B. (1997). Distinction in America? Recovering Bourdieu's theory of tastes from its critics. Poetics, 25(2/3), 93-120. doi:10.1016/S0304422X(97)00010-7

Holt, K., Shehata, A., Strömbäck, J., \& Ljungberg, E. (2013). Age and the effects of news media attention and social media use on political interest and participation: Do social media function as leveller? European Journal of Communication, 28(1), 19-34. doi:10.1177/0267323112465369

Horowitz, E., \& Mindich, D. T. (2007). Tuned out: Why Americans under 40 don't follow the news. Journal of Communication, 57(1), 175-176. doi:10.1111/ j.1460-2466.2006.000339_2.x

Hovden, J. F., \& Moe, H. (2017). A sociocultural approach to study public connection across and beyond media: The example of Norway. Convergence, 23(4), 391-408. doi:10.1177/1354856517700381

Kalmus, V., Realo, A., \& Siibak, A. (2011). Motives for Internet use and their relationships with personality traits and socio-demographic factors. Trames, 15(4), 385-403. doi:10.3176/tr.2011.4.04

Katz, E., Blumler, J. G., \& Gurevitch, M. (1973). Uses and gratifications research. Public Opinion Quarterly, 37, 509-523. doi:10.1086/268109

Kim, S. J. (2014). A repertoire approach to cross-platform media use behavior. New Media \& Society, 18(3), 353-372.

Kohut, A. (2013). Pew surveys of audience habits suggest perilous future for news. Poynter. Retrieved from https://www.poynter.org/news/pew-surveysaudience-habits-suggest-perilous-future-news

Ksiazek, T. B., Malthouse, E. C., \& Webster, J. G. (2010). News-seekers and avoiders: Exploring patterns of total news consumption across media and 
the relationship to civic participation. Journal of Broadcasting \& Electronic Media, 54(4), 551-568. doi:10.1080/08838151.2010.519808

LaRose, R., \& Eastin, M. S. (2004). A social cognitive theory of Internet uses and gratifications: Toward a new model of media attendance. Journal of Broadcasting \& Electronic Media, 48(3), 358-377. doi:10.1207/ s15506878jobem4803_2

Lee, H., \& Yang, J. (2014). Political knowledge gaps among news consumers with different news media repertoires across multiple platforms. International Journal of Communication, 8, 597-617. Retrieved from http://ijoc.org/index.php/ijoc/article/view/2455

Lindell, J., \& Hovden, J.-F. (2016). Distinktioner i medievälfärdsstaten [Distinctions in the media welfare state]. In J. Ohlsson, H. Oscarsson, \& M. Solevid (Eds.), Ekvilibrium (pp. 315-329). Gothenburg: SOMinstitutet.

Lindell, J., \& Hovden, J. F. (2017). Distinctions in the media welfare state: Audience fragmentation in postegalitarian Sweden. Media, Culture \& Society, 40, 1-17.

Lindell, J., \& Sartoretto, P. (2017). Young people, class and the news. Journalism Studies. doi:10.1080/ 1461670X.2017.1310628

Meyen, M., Pfaff-Rüdiger, S., Dudenhöffer, K., \& Huss, J. (2010). The internet in everyday life: A typology of Internet users. Media, Culture \& Society, 32(5), 873-882. doi:10.1177/0163443710374792

Morley, D. (2009). For a materialist non-media-centric mediastudies. Television \& New Media, 10, 114-116.

Newman, N., Fletcher, R., Kalogeropoulos, A., Levy, D. a. L., \& Kleis Nielsen, R. (2017). Reuters Institute digital news report 2017. Reuters Institute for the Study of Journalism. Retrieved from https://reutersinstitute. politics.ox.ac.uk/sites/default/files/Digital\%20News\% 20Report\%202017\%20web_0.pdf

Ohlsson, J., Lindell, J., \& Arkhede, S. (2017). A matter of cultural distinction: News consumption in the online media landscape. European Journal of Communication, 32(2), 116-130. doi:10.1177/ 0267323116680131

Pariser, E. (2011). The filter bubble: How the new person- alized web is changing what we read and how we think. London: Penguin Books.

Prieur, A., \& Savage, M. (2013). Emerging forms of cultural. European Societies, 15(2), 246-267. doi:10.1080/14616696.2012.748930

Robinson, L. (2009). A taste for the necessary: A Bourdieuian approach to digital inequality. Information Communication and Society, 12(4), 488-507. doi:10.1080/13691180902857678

Schrøder, K. C. (2011). Audiences are inherently crossmedia: Audience studies and the cross-media challenge. Communication Management Quarterly, 18(VI), 5-28.

Slots- og Kulturstyrelsen. (2017). Rapportering om mediernes udvikling 2017. [English title missing]. Retrieved from https://slks.dk/mediernes-udvikling2017

Strömbäck, J., Djerf-Pierre, M., \& Shehata, A. (2013). The dynamics of political interest and news media consumption: A longitudinal perspective. International Journal of Public Opinion Research, 25(4), 414-435.

Sveningsson, M. (2015). "It's only a pastime, really": Young people's experiences of social media as a source of news about public affairs. Social Media + Society, 1(2), 1-11. doi:10.1177/2056305115604855

Tewksbury, D. (2005). The seeds of audience fragmentation: Specialization in the use of online news sites. Journal of Broadcasting \& Electronic Media, 49, 332-348. doi:10.1207/s15506878jobem4903_5

Trilling, D., \& Schoenbach, K. (2013). Skipping current affairs: The non-users of online and offline news. European Journal of Communication, 28(1), 35-51. doi:10.1177/0267323112453671

York, C., \& Scholl, R. M. (2015). Youth antecedents to news media consumption parent and youth newspaper use, news discussion, and long-term news behavior. Journalism and Mass Communication Quarterly, 92(3), 681-699. doi:10.1177/1077699015588191

Zillien, N., \& Hargittai, E. (2009). Digital distinction: Status-specific types of Internet usage. Social Science Quarterly, 90(2), 274-291. doi:10.1111/j.15406237.2009.00617.x

\section{About the Author}

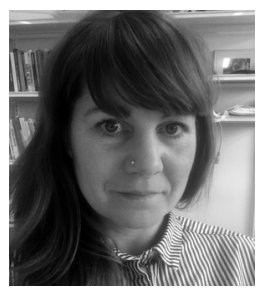

Jannie Møller Hartley is an associate professor in journalism at the department of Communication and Arts, Roskilde University, and the head of Journalism studies. Her research is focused on digital news production and consumption in the digital sphere. She is the author of the book 'Nyheder på Intternettet (Online News Production), and is currently working on a larger project on cross media news consumption and civic engagement in Denmark, financed by Media Power and Communication (MMK), Roskilde University. 